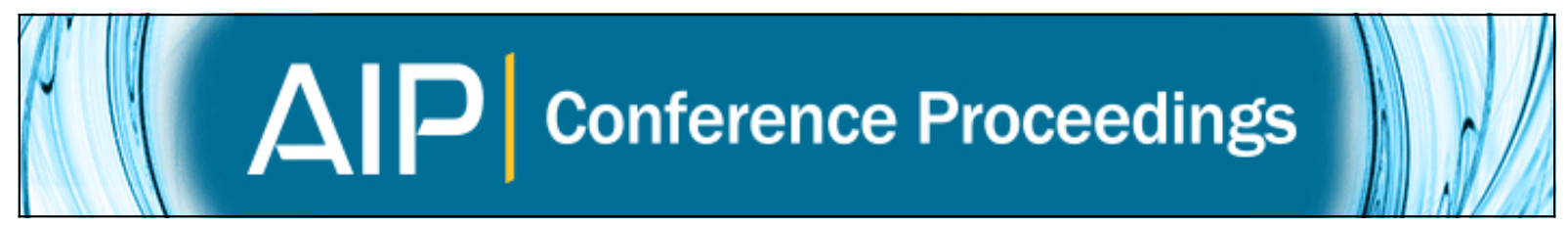

\title{
Multi-species nucleation rates in CLOUD
}

J. Almeida, J. Curtius, J. Kirkby, and CLOUD Collaboration

Citation: AIP Conference Proceedings 1527, 326 (2013); doi: 10.1063/1.4803269

View online: http://dx.doi.org/10.1063/1.4803269

View Table of Contents: http://scitation.aip.org/content/aip/proceeding/aipcp/1527?ver=pdfcov

Published by the AIP Publishing

\section{Articles you may be interested in}

Thermodynamic modeling of atmospheric aerosols: $0-100 \%$ relative humidity

AIP Conf. Proc. 1527, 441 (2013); 10.1063/1.4803299

Ternary $\mathrm{H} 2 \mathrm{SO} 4$ - $\mathrm{H} 2 \mathrm{O}-\mathrm{NH} 3$ neutral and charged nucleation rates for a wide range of atmospheric conditions

AIP Conf. Proc. 1527, 310 (2013); 10.1063/1.4803265

Assessment of aerosol hygroscopic growth using an elastic LIDAR and BRAMS simulation in urban metropolitan areas

AIP Conf. Proc. 1531, 360 (2013); 10.1063/1.4804781

Hyperspectral retrieval of surface reflectances: A new scheme

AIP Conf. Proc. 1531, 51 (2013); 10.1063/1.4804705

Experimental evaluation of the pressure and temperature dependence of ion-induced nucleation

J. Chem. Phys. 133, 124315 (2010); 10.1063/1.3490354 


\title{
Multi-species nucleation rates in CLOUD
}

\author{
J. Almeida ${ }^{* \dagger}$, J. Curtius ${ }^{\dagger}$, J. Kirkby* and the CLOUD collaboration \\ ${ }^{*}$ CERN, Geneva, Switzerland \\ ${ }^{\dagger}$ Institute for Atmospheric and Environmental Sciences, Goethe University of Frankfurt, Germany
}

\begin{abstract}
In the CLOUD experiment at CERN we have been investigating the chemical species that are most important to atmospheric new particle formation. Sulphuric acid plays a key role in aerosol nucleation, but other vapours and ions can strongly enhance the formation rate. Quantifying the contribution of each species and the conditions under which each one is important is a major challenge and requires sophisticated laboratory experiments. The CLOUD chamber, a 3m stainless steel aerosol chamber exposed to a pion beam from the CERN Proton Synchrotron, can create a precisely controlled atmospheric environment over a wide range of temperatures, ionisation states and gas mixtures, while keeping contamination levels extremely low. CLOUD has studied a range of vapour species at atmospheric concentrations, including, in various combinations, sulphuric acid, ammonia, dimethylamine and alpha-pinene. The effect of ions on the nucleation rates has been measured for all species since it is of considerable interest as a possible link between galactic cosmic rays and climate[1]. This work will present an overview of the nucleation rates measured in CLOUD and compare them with atmospheric observations.
\end{abstract}

Keywords: Aerosol particle nucleation, CLOUD chamber experiment, dimethylamine, alphapinene, sulphuric acid, ammonia, ions, galactic cosmic rays

PACS: $82.60 . \mathrm{Nh}$

\section{INTRODUCTION}

Clouds play an important role on the Earth's radiative balance and hence climate. Clouds form on aerosol particles, and increases of aerosol concentrations make clouds brighter and extends their lifetimes [2] creating a net climate cooling. High concentrations of aerosol also reduce visibility and can be a source of health problems. Studying aerosol formation helps to understand how anthropogenic and non-anthropogenic factors such as deforestation, agriculture, livestock, industry, galactic cosmic rays and corona discharges (such as in power lines) can affect the environment. Explaining how new aerosol are formed and under what conditions is one of the main challenges of the CLOUD experiment at CERN.

\section{CERN CLOUD EXPERIMENT}

The main instrument of the CLOUD experiment is a $3 \mathrm{~m}$ diameter electro-polished stainless steel chamber with a volume of $26.1 \mathrm{~m} 3$, surrounded by a thermal housing, with air circulating in the space between the chamber and the insulation for the precise thermal control.

In CLOUD we have studied some of the trace vapours thought to be most important for atmospheric nucleation, including sulphuric acid, ammonia, dimethylamine

Nucleation and Atmospheric Aerosols

AIP Conf. Proc. 1527, 326-329 (2013); doi: 10.1063/1.4803269

(C) 2013 AIP Publishing LLC 978-0-7354-1152-4/\$30.00 
TABLE 1. Nucleation systems studied in the CLOUD experiment (DMA, dimethylamine; AP, alpha-pinene).

\begin{tabular}{lll}
\hline Type & System & Comments \\
\hline Binary & $\mathrm{H} 2 \mathrm{SO} 4+\mathrm{H} 2 \mathrm{O}$ & - \\
Ternary & $\mathrm{H} 2 \mathrm{SO} 4+\mathrm{H} 2 \mathrm{O}+\mathrm{NH} 3$ & - \\
Ternary & $\mathrm{H} 2 \mathrm{SO} 4+\mathrm{H} 2 \mathrm{O}+\mathrm{DMA}$ & - \\
Quaternary & $\mathrm{H} 2 \mathrm{SO} 4+\mathrm{H} 2 \mathrm{O}+\mathrm{DMA}+\mathrm{NH} 3$ & - \\
Ternary & $\mathrm{H} 2 \mathrm{SO} 4+\mathrm{H} 2 \mathrm{O}+\mathrm{AP}$ & Pure ozonolysis $(\mathrm{O} 3+\mathrm{H} 2)$ \\
Ternary & $\mathrm{H} 2 \mathrm{SO} 4+\mathrm{H} 2 \mathrm{O}+\mathrm{AP}$ & Pure OH (HONO + UV) \\
Ternary & $\mathrm{H} 2 \mathrm{SO} 4+\mathrm{H} 2 \mathrm{O}+\mathrm{AP}$ & Mixed (O3 + UV) \\
Quinary & $\mathrm{H} 2 \mathrm{SO} 4+\mathrm{H} 2 \mathrm{O}+\mathrm{AP}+\mathrm{DMA}+\mathrm{NH} 3$ & Hyytiälä simulation \\
\hline
\end{tabular}

(also representative of other amines) and alpha-pinene (representing other low volatile monoterpenes) (Table 1). To evaluate the effect of ions on nucleation most of our runs were repeated with different ionisation states, as follows:

- Neutral: all ions are removed by applying $20 \mathrm{kV} / \mathrm{m}$ electric field to the chamber;

- Galactic Cosmic Rays: the CLOUD chamber is exposed to galactic cosmic rays;

- CHarged or beam conditions: a $\pi^{+}$beam from the CERN PS irradiates the chamber, creating ion concentrations similar to those of the upper troposphere.

Trace gas were studied at mixing ratios between a few pptv and about 1000 pptv. The instruments used to analyse these gases included a LOng Path Absorption Photometer (LOPAP) [3] , an Ion Chromatograph (IC) [4] and a Proton-TRansfer Mass Spectrometer (PTR-MS) [5]. Sulphuric acid was measured by a Chemical Ionization Mass Spectrometer (CIMS) sensitive to acid concentrations between a few $10^{5}$ and $10^{9} \mathrm{~cm}^{-3}$. All the nucleation rates were calculated from a TSI $37762.5 \mathrm{~nm}$ ultra-fine particle counter and corrected to the threshold of $1.7 \mathrm{~nm}$ using theoretical calculations.

\section{Studied Nucleation Mechanisms}

Binary Nucleation An ultra-clean chamber is required to study binary nucleation since contaminants at mixing ratios of only a few pptv can produce huge enhancements of the nucleation rate. Simultaneous measurement of the molecular composition of the nucleating clusters has allowed us to confirm their binary composition, or otherwise. CLOUD has been able to record an unprecedented dataset of binary or quasi-binary nucleation rates and, for the first time, it can be been seen how weakly the pure binary system nucleates when compared with atmospheric boundary layer observations [6]. Binary nucleation was widely studied by varying the $\mathrm{H}_{2} \mathrm{SO}_{4}$ concentrations from $10^{6}$ to $10^{9} \mathrm{~cm}^{-3}$ at different temperatures, ranging from $208 \mathrm{~K}$ to $298 \mathrm{~K}$.

Nucleation with ammonia The full range of tropospheric temperatures was explored by varying sulphuric acid concentration in the presence of ammonia levels ranging from contaminant $\left(<10^{-2}\right.$ pptv at low temperatures) to a few ppbv (well above sat- 


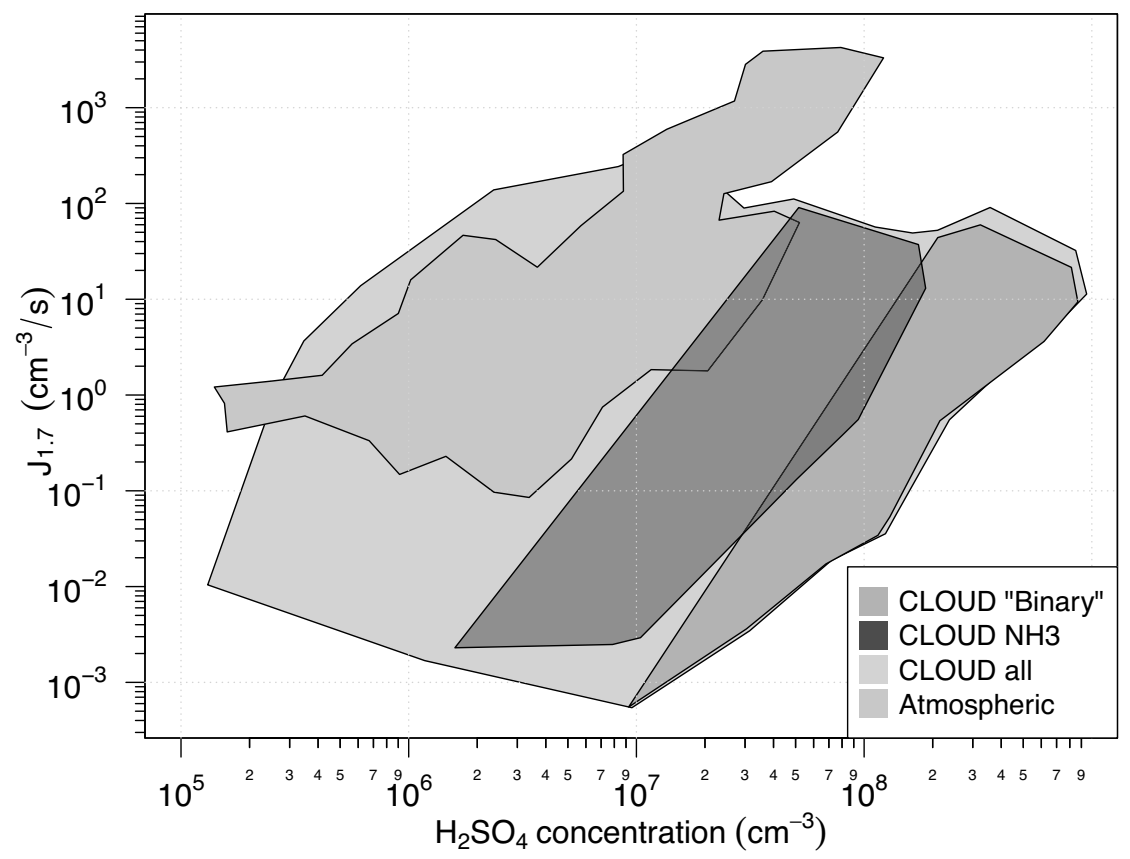

FIGURE 1. Nucleation rates explored in CLOUD at 278K, compared with atmospheric observations.

uration of the nucleation rate). Although ammonia strongly enhances the nucleation rate, it fails to account for atmospheric observations [6].

Nucleation with dimethylamine Dimethylamine (DMA) was chosen as representative of other amines and it's effect on the nucleation of sulphuric acid particles was extensively studied in CLOUD at $278 \mathrm{~K}$, characteristic of boundary layer temperatures. The DMA levels explored range from sub-pptv to 100 pptv. The effect of amines in association with ammonia and alpha-pine was also investigated.

Nucleation with alpha-pinene The CLOUD chamber features a unique fibre optic system that allows regulation of the UV light intensity inside the chamber without any parasitic thermal influence. This is used for precise control and timing of photolytically-induced gas phase reactions. Several different oxidation mechanisms were investigated to uncover their relative importance in the atmosphere (Table 1): pure ozonolysis (O3 with an $\mathrm{OH}$ scavenger, in the dark), pure $\mathrm{OH}$ (produced by photolytic dissociation of HONO) and mixed (photolytic dissociation of O3).

\section{RESULTS OVERVIEW}

The regions of nucleation rates measured in CLOUD at $278 \mathrm{~K}$ are shown in Fig. 1. CLOUD has measured nucleation rates over more than five orders of magnitude and spanned the region of atmospheric sulphuric acid concentrations. Our previous work [6] has shown that binary and ammonia ternary nucleation lie in the red and blue regions, respectively, indicated in Fig. 1. The new results we will present here cover the grey 
region and encompass the atmospheric observations. Our results will shed new light on the role of various species - sulphuric acid, ammonia, amines and oxidised organics, together with ions from galactic cosmic rays - in aerosol particle nucleation in the atmospheric boundary layer.

\section{ACKNOWLEDGMENTS}

We would like to thank CERN for supporting CLOUD with important technical and financial resources, and for providing a particle beam from the CERN Proton Synchrotron. This research has received funding from the EC Seventh Framework Programme (Marie Curie Initial Training Network "CLOUD-ITN" no. 215072, MC-ITN "CLOUD-TRAIN" no. 316662, and ERC-Advanced "ATMNUCLE" grant no. 227463), the German Federal Ministry of Education and Research (project nos. 01LK0902A and 01LK1222A), the Swiss National Science Foundation (project nos. 200020_135307 and 206620_130527), the Academy of Finland (Center of Excellence project no. 1118615), the Academy of Finland (135054, 133872, 251427, 139656, 139995, 137749, 141217, 141451), the Finnish Funding Agency for Technology and Innovation, the Nessling Foundation, the Austrian Science Fund (FWF; project no. P19546 and L593), the Portuguese Foundation for Science and Technology (project no. CERN/FP/116387/2010), the Swedish Research Council, Vetenskapsärdet (grant 2011-5120), the Presidium of the Russian Academy of Sciences and Russian Foundation for Basic Research (grants 08-02-91006-CERN and 12-02-91522-CERN), and the U.S. National Science Foundation (grants AGS1136479 and CHE1012293).

\section{REFERENCES}

1. K. Carslaw, Nature 460, 322-333 (2009).

2. U. Lohmann, and J. Feichter, Atmos. Chem. Phys. 5, 715-737 (2005).

3. F. Bianchi, et al., Atmos. Meas. Tech. 5, 1719-1725 (2012).

4. A. P. Praplan, et al., Atmos. Meas. Tech. 5, 2161-2167 (2012).

5. M. Norman, et al., Atmos. Meas. Tech. 9, 2635-2645 (2009).

6. J. Kirkby, et al., Nature 476, 429-433 (2011). 